\title{
Interaction of arbuscular mycorrhizal inoculants and chicken manure in avocado rootstock production
}

\author{
Y. Carreón-Abud ${ }^{1}$, M. Vega-Fraga ${ }^{1}$ and M.E. Gavito ${ }^{2 *}$ \\ ${ }^{1}$ Laboratorio de Genética y Microbiología. Facultad de Biología. Universidad Michoacana de San Nicolás de \\ Hidalgo.'Instituto de Investigaciones en Ecosistemas y Sustentabilidad, Universidad Nacional Autónoma de México- \\ Campus Morelia. C.P. 58090. Morelia, Michoacán, Mexico.*Corresponding author: mgavito@cieco.unam.mx
}

\begin{abstract}
The nursery stage of avocado plant production provides the best opportunity for introducing mycorrhizal inoculants. Three single-species inocula (Acaulospora laevis, Cetraspora pellucida and Pacispora scintillans), an inoculum using a consortium of these three species, an inoculum from a native orchard mycorrhizal community and an uninoculated field soil control were compared experimentally using a factorial experimental design in combination with 8,17 , or $25 \mathrm{~g}$ of chicken manure per $\mathrm{kg}$ soil. The height, stem diameter, number of leaves, pathogen damage level, and herbivory in "criollo" avocado rootstocks were recorded every two weeks. The leaf area, biomass and mycorrhizal colonization of the roots were measured 7 months after sowing. Overall, responses to mycorrhizal inoculation were minor and increasing fertilization negatively affected most variables. The best inocula were the Cetraspora pellucida and native orchard mycorrhizal community inocula. The negative effects of high chicken manure fertilization on plant growth and health have important implications for nursery management because chicken manure is a preferred fertilizer.
\end{abstract}

Keywords: Consortium, health, herbivory, inoculum, nursery

\section{Introduction}

Mexico, and the state of Michoacán within Mexico, is the world's largest avocado producer (Anguiano et al., 2006; SIAP-SAGARPA, 2010). The production of avocado in large plantations has been continuously expanding within Michoacán (Bravo-Espinosa et al., 2014) and in other regions of the country where the environmental conditions are favorable for this crop.
Nurseries that produce avocado plants are in high demand and sell millions of 1-2-year-old rootstocks throughout the country each year. Nurseries in this region are well known for their production of high quality plants and can offer conventionally and organically produced plants. 
Recently, many commercial, national and foreign arbuscular mycorrhizal inoculants have been promoted for use in nurseries as biofertilizers and plant growth promoters. However, little information is available regarding their effectiveness for promoting avocado growth or health. The success of mycorrhizal inoculants depends on the conditions in which they will be applied (Verbruggen et al., 2013). These conditions include the target crop and the local biota that are already present in the soil or growth substrate. Particularly, foreign inoculants represent a potential sanitary risk because they are introduced without previous performance tests and before determining their invasive nature when interacting with the local biota. In contrast, locally produced inoculants are already adapted to the environmental conditions and to the local biota. Thus, their production may become a source of local employment and benefit, which would reduce production costs and the actual dependency on external and expensive supplies.

The use of local fertilizer sources, ideally organic fertilizers, may complement the contributions of arbuscular mycorrhizal fungi (AMF) inoculants and ensure adequate nutrition under the same sustainable production scheme. However, only a few alternatives have been tested in nurseries and most of the published information regarding trials testing of AMF inoculants was conducted in other countries with different cultural practices. Although this information is useful, it is old (Menge et al., 1978, 1980, Silva and Siqueira 1991; Vidal et al., 1992; Da Silveira et al., 2002) or has been published in brief format in a thesis, an abstract or proceedings (Reyes-Alemán et al., 1998, 2001; Mattar et al., 2003; MontañezOrozco, 2009; Montoya and Osorio, 2009). Some important differences occur when examining the style of rootstock production in Mexico. Particularly, the nurseries of Michoacán merit further research. The first difference is the use of fresh soil, often forest soils, as the main potting media. This use implies that there are native AMF communities and other biota present because the soil is not disinfected or fumigated. The second difference is the hybrid nature of rootstock production, regardless of the "organic" and "conventional" labels, due to the widespread use of copper-based fungicides (allowed in organic production) and organic fertilizers with manure or composted materials in both production systems. The last difference is the germination of "criollo" avocado seeds that were obtained from several wild native varieties of avocado by natural pollination that are later grafted with Hass varieties. Germination may take 1-2 months and plants will develop very few thick roots within the first 3 months. Thus, introducing mycorrhizal inoculants at early stages without disturbing the root system becomes important.

The fact that the main substrate for current rootstock production involves fresh field soil instead of potting media suggests that inoculation is not needed unless native AMF communities are not efficient or induce growth depressions. In addition, high fertilizer applications are generally used in nurseries to ensure vigorous growth. In this case, mycorrhizal inoculation seems unnecessary and redundant for nursery production. Many studies have shown that $\mathrm{P}$ fertilizer negatively affects mycorrhizal development in most plants (Treseder, 2004). Thus, it is generally believed that mycorrhizae and fertilization are not compatible and that only one should be used. However, other evidence has suggested that mycorrhizae can successfully interact with moderate $P$ fertilizer applications and benefit simple fertilizer applications by promoting other environmental services (Gianninazzi et al., 2010).

Thus, it is important to evaluate the following questions: 1) are mycorrhizal inoculants needed? 2) are the "criollo" avocado rootstocks responsive to mycorrhizal inoculation? and 3) does mycorrhizal 
inoculation have a negative, neutral or positive interaction with the native AMF and the most commonly used organic fertilizer? This study was designed to test the effectiveness of newly developed local mycorrhizal inoculants in combination with chicken manure, which is a locally affordable and accessible source of organic fertilizer, on the growth and health of "criollo" avocado nursery plants.

\section{Materials and Methods}

\subsection{Production of the local inoculants}

Soil samples were collected in Zacán, a municipality of Los Reyes Michoacán, between April and November of 2008 in an avocado region in which the landscape is dominated by avocado orchards and a mixture of pine forests and maize fields. Propagation pots were prepared by mixing field soil and sand at a ratio of 3:1 and by growing Brachiaria decumbens as a host plant for 3 months. Watering was suspended to induce sporulation, and after 3 weeks, the spores were extracted by wet sieving and decanting (Gerdemann and Nicholson, 1963). The most abundant and preserved spore morphotypes were mounted on slides to determine their identities according to different morphological criteria.

Spores of the same type were directly added to the roots of recently germinated alfalfa plants by pipetting. Next, the plants were immediately place in tubes of autoclaved soil and were maintained in a greenhouse with adequate water and minimal fertilization. Eight weeks later, a root sample was collected, stained (Phillips and Hayman, 1970) and mounted on the slides to determine mycorrhizal colonization. Successful pure cultures were transplanted to larger pots with additional autoclaved soil, and new Brachiaria decumbens seeds were planted to multiply the isolate. At this stage, three isolates were selected for the experiment, Cetraspora pellucida, Acaulospora laevis and Pacispora scintillans. These isolates were allowed to continue to a second propagation. In addition, a consortium was initiated by mixing these three inoculants and a full native arbuscular mycorrhizal community inoculum made from a composite soil sample from Zacán. The full native arbuscular mycorrhizal community inoculum from Zacán included 20 spore morphotypes: Acaulospora delicata, A. denticulata, A. foveata, A. koskei, A. laevis, A. rehmii, A. scrobiculata, A. spinosa, Ambispora leptoticha, Diversispora spurca, Gigaspora albida, Racocetra fulgida, R. gregaria, Rhizophagus aff. fasciculatus, Funneliformis geosporum, F. mosseae, Glomus microaggregatum, Pacispora scintillans, Sclerocystis sinuosa and Septoglomus viscosum,. Eight weeks later, the soils and roots from these cultures were used to establish large propagation trays with grass as a host plant to obtain several kilograms of the desired inoculant for the experiment. After eleven weeks (8 wks growth plus 3 wks desiccation), the inoculants were ready. The roots were chopped and mixed thoroughly with the soil.

\subsection{Experimental design and set up}

A full factorial experimental design was used with mycorrhizal inoculation and fertilization as factors. Mycorrhizal inoculation consisted of six treatments: single inocula of Cetraspora pellucida, Acaulospora laevis and Pacispora scintillans, inoculation with a consortium made from these three isolates, inoculation with a native arbuscular mycorrhizal fungi community from avocado orchards and a fresh soil that was used in the nursery as a control. The native arbuscular mycorrhizal community soil from the nursery soil included 15 spore morphotypes: Acaulospora laevis, A. scrobiculata, A. spinosa, Entrophospora infrequens, 
Gigaspora sp. 1, G. sp. 2, Racocetra verrucosa, Scutellospora scutata, S. sp.1, S. sp.2, Rhizophagus clarus, $R$. aff. fasciculatus, Funneliformis mosseae, F. geosporum, and Septoglomus viscosum.

Chicken manure, the most widely used organic fertilizer in the region due to its affordability, reliability and easy production, was used to fertilize the soil and was incorporated to the soil in three doses before filling the nursery bags. The three doses included half the normal dose used in the nursery ( $8.3 \mathrm{~g} \mathrm{~kg}^{-1}$, low), the normal dose (16.6 $\mathrm{g} \mathrm{kg}^{-1}$, medium) and 1.5 times the dose used in the nursery ( $25 \mathrm{~g} \mathrm{~kg}^{-1}$, high). Chicken manure contained $9.3 \pm 0.92 \mathrm{mg} \mathrm{g}^{-1}$ available $\mathrm{N}$ and $7.68 \pm 0.42$ $\mathrm{mg} \mathrm{g}^{-1}$ available $\mathrm{P}$ on a dry weight basis. Fresh soil from the region (an andosol; FAO/WRB) was collected from a nearby forest with a $\mathrm{pH}$ of $6.13 \pm 0.14$, a soil organic matter content of $10.1 \pm 2.8 \%$, and an available P content of $7.6 \pm 7.4$ (Bray available P). This soil was mixed with the defined fertilizer dose and used to fill half the volume of black plastic nursery bags. Three "criollo" avocado seeds that were previously coated with the appropriate inoculum were planted in each bag and were covered with the same soils for a total soil mass of $4 \mathrm{~kg}$. Seeds were coated by dipping them first in an adherent solution made from Opuntia cactus and then in the inoculum. The coating was allowed to dry and the procedure was repeated. The seeds received 15-20 g of inoculum with this procedure that we have found is successful at producing abundant mycorrhizal colonization in avocado plants. The control treatment was coated with the same soil that was used in the rest of the pot. Generally, nurseries pregerminate the seeds in a soil bed and transplant them into soil bags after they have reached a height of approximately 20 $\mathrm{cm}$. However, we sowed the seeds directly in the bags to increase the chances of root colonization by the inoculated species that were applied in the coating. The chicken manure was applied without any previous composting treatment and directly to the soil surface (the method generally used in nurseries). Overall, nine replicates of each treatment combination were conducted.

The plants were maintained in a nursery in Ziracuaretiro, Michoacán, under ambient environmental conditions and under an open canopy while only providing the required water. After germination (1-2 months after sowing), two seedlings were removed so that only one remained in each bag. The remaining plants were allowed to establish for one month to achieve homogeneous growth. Next, the plant heights, diameters, numbers of leaves and the proportions of leaves with herbivory or pathogen damage were monitored every 15 days from day 90 to day 202 after sowing. After 222 days, the plants were harvested and the leaf area, shoot weight, root weight, and intraradical mycorrhizal colonization were measured for blocks of plants (one of each treatment for each time) given the long processing time. All leaves were detached from the stem and extended on plastic sheets for photographing. The leaf area was calculated from the photographs using ImageJ Image Processing and Analysis in Java ${ }^{\circledR}$. The shoots were dried until a constant weight was achieved. The roots were carefully extracted from the soil, washed, blotted and weighed fresh.

A representative root sample was collected for mycorrhizal colonization after chopping the root system into short segments and allowing them to mix freely in a large beaker of water. The sample was weighed and stored in a 1:1 alcohol to water mixture until further processing. The remaining roots were collected in a sieve, blotted with napkins and dried to a constant weight. For mycorrhizal colonization, the roots were rinsed and stained as previously described (Phillips and Hayman, 1970), including a step soaking the roots for several hours in hydrogen peroxide to bleach the dark roots. After staining, the roots were mounted on slides and scored for mycorrhizal colonization as described by McGonigle et al. (1990). 


\subsection{Statistical analysis}

Periodical measurements were analyzed with repeated analyses of variance using the inoculation and fertilization treatments as factors. The variables that were measured at harvest were analyzed using a two-way analysis of variance (ANOVA) that included inoculation and fertilization. Significant differences $(\mathrm{P}<0.05)$ were further examined using Tukey's test. The data were transformed as required, mainly with $\log$ transformations and arcsine transformations for the colonization percentage values. All of the statistic tests were performed by using the Statistix 7 software.

\section{Results}

Our results showed minor responses of the "criollo" avocado plants to the different inoculation and fertilization treatments during the first few months of growth in the nursery. The variables that were measured every two weeks showed significant main effects and factor interactions (Table 1), but clearly the most significant differences were found between the fertilization treatments.

The most consistent and relevant information from periodical measurements was that increasing levels of fertilization with chicken manure negatively affected most of the measured variables. The plant height, stem diameter, and number of leaves showed a negative response to increasing levels of chicken manure. The differences among the inoculation treatments were often small, with nearly identical heights, stem diameters, numbers of leaves and herbivore and pathogen attack for most of the sampling dates. Therefore, although several factor interactions were statistically significant, only stem diameter, which is recognized by rootstock producers as the best measure of plant growth and vigor during the nursery stage, is shown to represent the similarity and the small differences among treatments along the periodical measurements (Figure 1). Stem diameter was larger in plants colonized by the native AMF community, and inoculated with Cetraspora pellucida and Pacispora scintillans when the plants were grown with low fertilization. There were no differences between fertilization treatments for the other inoculation treatments. The treatment with the smallest stem diameter was the consortium.

The proportion of leaves under herbivore (Figure 2a) or pathogen attack (Figure 2b) presented the same negative response to increasing fertilizer. Here, the periodical measurements are not shown. Instead, only the final measurements at harvest are shown, where the differences were more marked. There were significant interactions between the inoculation by fertilization (Table 2) regarding the plant height, stem diameter, number of leaves, proportion of leaves attacked by herbivores, the proportion of leaves attacked by pathogens, and the total shoot biomass at harvest. After seven months, the mycorrhizal inoculation treatments still had minor effects on all of the variables (Table 2). In contrast, the fertilization treatments had stronger and more significant effects on some of the measured variables. Furthermore, the interactions were nearly significant for the leaf area and the mycorrhizal colonization percentages, but the observed variations were larger. No significant differences were observed in root biomass.

The total biomass, shoot biomass and leaf area of the plants that were inoculated with different AMF depended on the level of fertilizer application. However, the differences among the treatments were small, which indicated that at this growth stage and at the original soil fertility levels, the "criollo" avocado plants received minimum benefits from the inoculation and fertilization treatments. Only the total biomass is shown here (Figure 3) because the shoot biomass and leaf area data were nearly identical to the total biomass. All plants became mycorrhizal (Figure 4) 
and well colonized. Inoculation with the different $\mathrm{AMF}$ increased the mycorrhizal colonization in most treatments relative to the control treatment, which only contained the propagules that were originally present in the soil. The tested fertilization levels did not affect the mycorrhizal colonization.

Table 1. Probabilities of significance for the main effects and factor interactions that resulted from repeated ANOVA measures of the variables that were measured every 15 days from day 90 to day 202 after sowing. Significant differences were accepted at $P<0.05$.

\begin{tabular}{|l|l|l|l}
\hline Variable & Inoculation & Fertilization & I x F \\
\hline Height & 0.915 & $<0.001$ & 0.023 \\
\hline Diameter & $<0.001$ & $<0.001$ & $<0.001$ \\
\hline Number of leaves & 0.035 & $<0.001$ & $<0.001$ \\
\hline $\begin{array}{l}\text { Leaves with } \\
\text { herbivore attack }\end{array}$ & 0.047 & 0.002 & $<0.001$ \\
\hline $\begin{array}{l}\text { Leaves with pathogen } \\
\text { attack }\end{array}$ & $<0.001$ & $<0.001$ & $<0.001$ \\
\hline
\end{tabular}

Table 2. Probabilities of significance for the main effects and factor interactions (ANOVA) of the variables measured at harvest on day 222 after sowing. Significant differences were accepted at $P<0.05$.

\begin{tabular}{|l|c|c|c|}
\hline \multicolumn{1}{|c|}{ Variable } & Inoculation & Fertilization & I x F \\
\hline Height & 0.285 & 0.100 & 0.012 \\
\hline Diameter & 0.329 & 0.577 & 0.019 \\
\hline Number of leaves & 0.405 & $<0.001$ & 0.034 \\
\hline $\begin{array}{l}\text { Proportion of leaves attacked by } \\
\text { herbivores }\end{array}$ & 0.067 & 0.098 & 0.002 \\
\hline $\begin{array}{l}\text { Proportion of leaves attacked by } \\
\text { pathogens }\end{array}$ & 0.266 & $<0.001$ & $<0.001$ \\
\hline Total biomass & 0.051 & 0.011 & 0.025 \\
\hline Mycorrhizal colonization & 0.011 & 0.256 & 0.116 \\
\hline
\end{tabular}




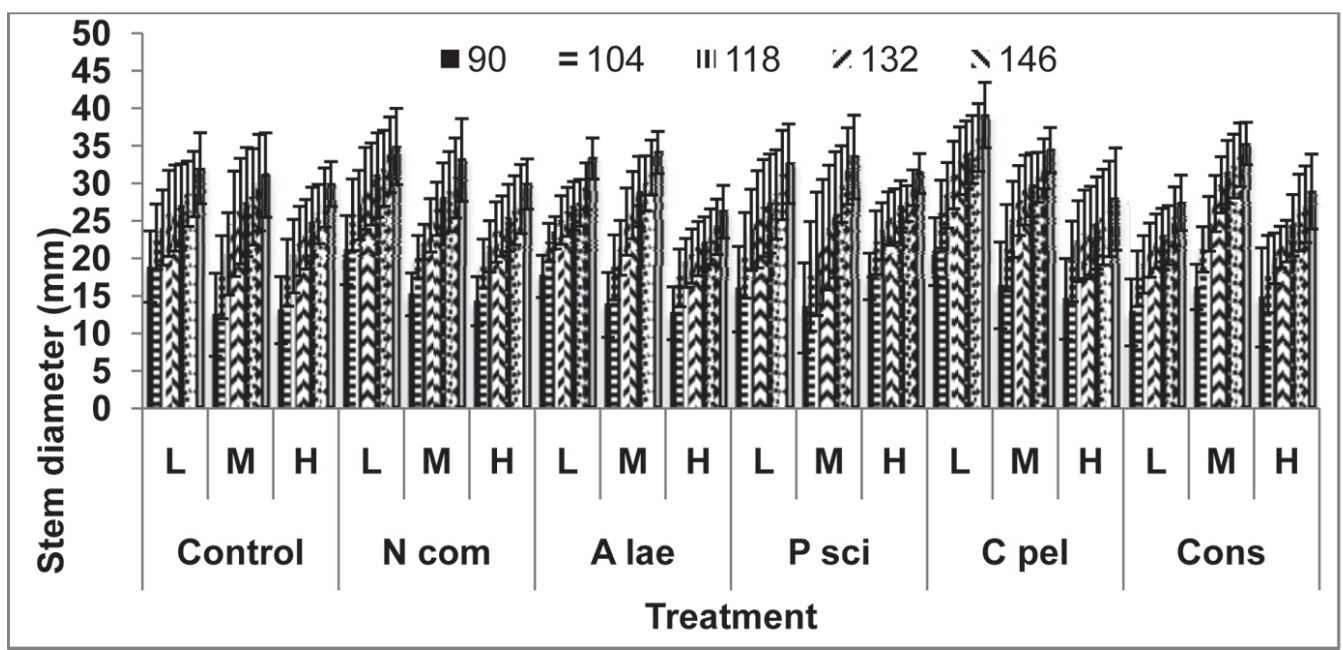

Figure 1. Means and standard errors $(\mathrm{n}=9)$ stem diameter measurements of avocado plants made every two weeks from day 90 to day 202 after sowing. Significant differences $(P<0.05)$ between treatments are not marked to ease visualization in the figure but are explained in text.

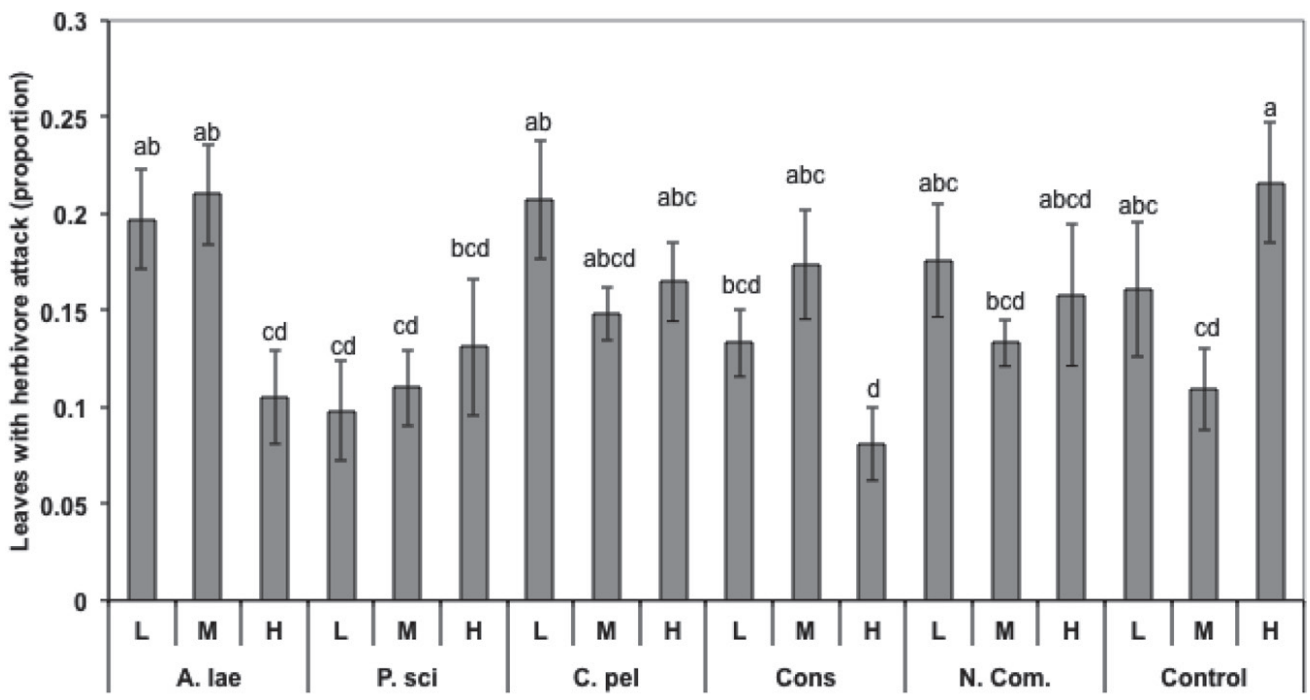

Figure 2a. The means and standard errors $(\mathrm{n}=9)$ for the proportions of avocado plant leaves that presented herbivore attack at harvest. Different lower-case letters indicate significant differences $(P<0.05)$ between the inoculation and fertilization treatment combinations. 


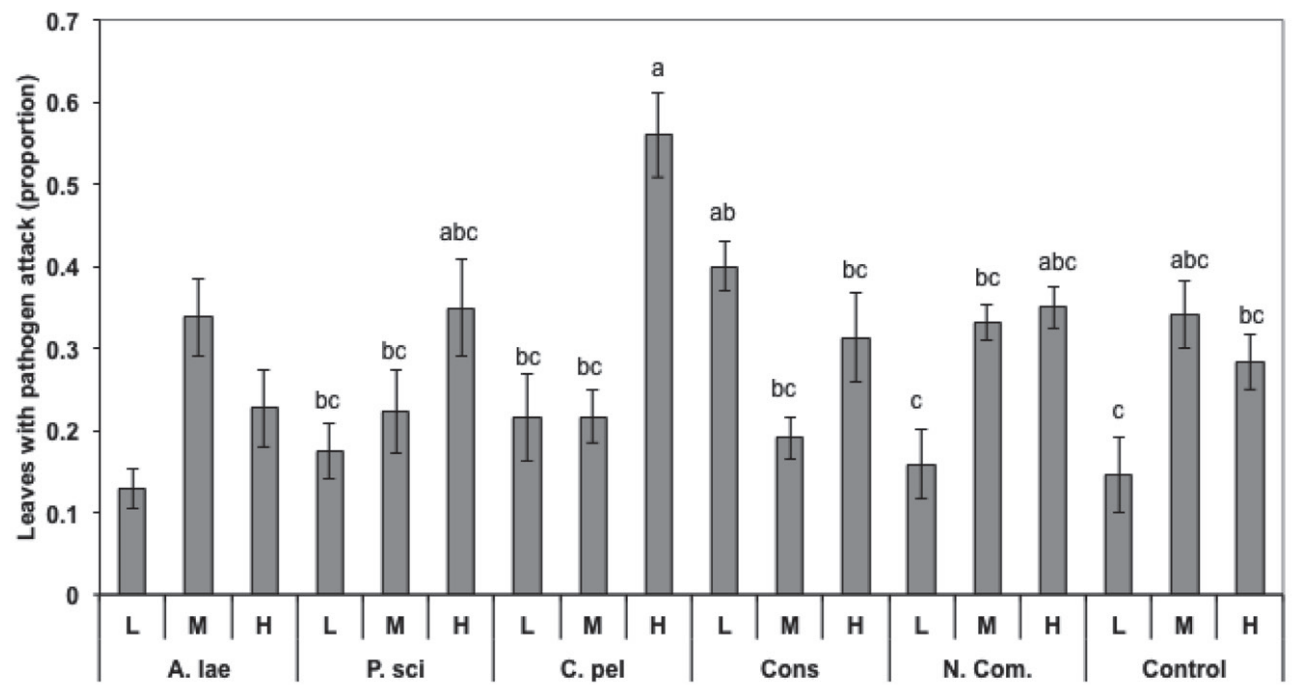

Figure 2b. Means and standard errors $(n=9)$ for the proportions of the avocado plant leaves that presented pathogen attack at harvest. Different lower-case letters indicate significant differences $(P<0.05)$ between the inoculation and fertilization treatment combinations.

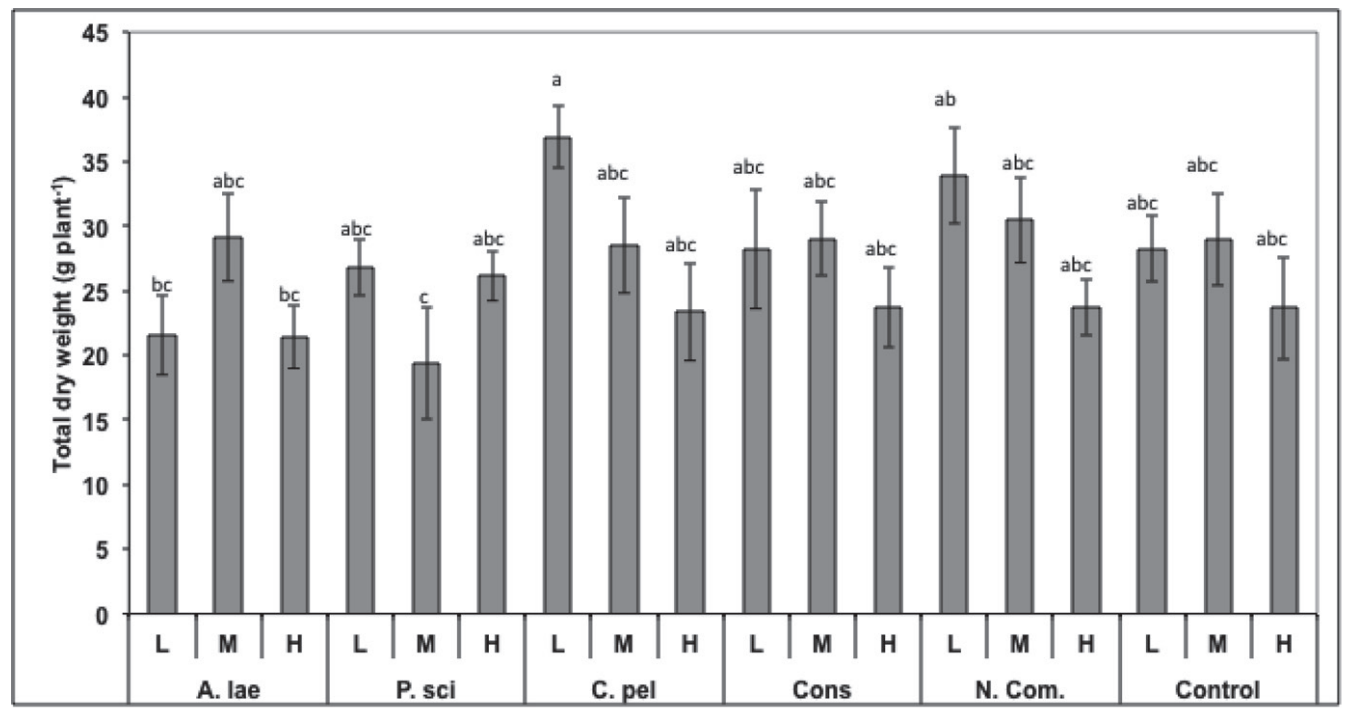

Figure 3. Means and standard errors $(n=9)$ of the total plant biomass of the avocado plants at harvest. Different lower-case letters indicate significant differences $(P<0.05)$ between the inoculation and fertilization treatment combinations. 


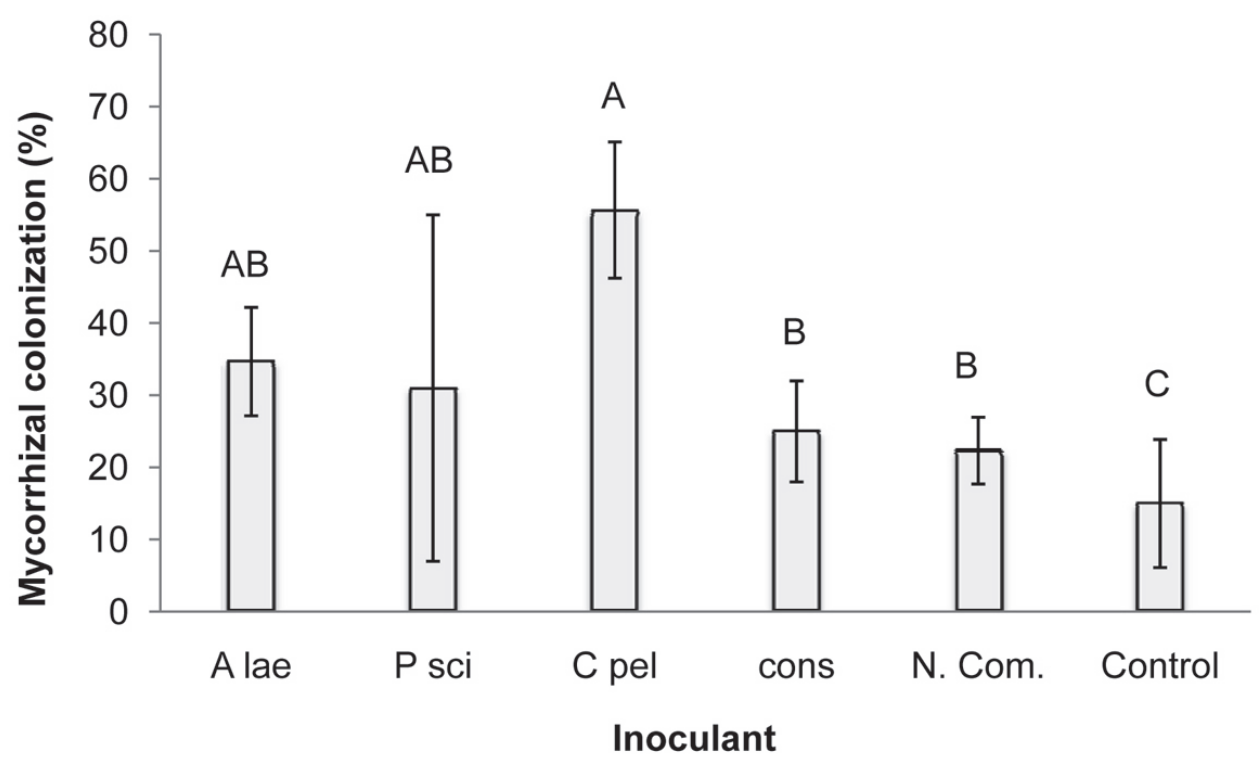

Figure 4. Means and standard errors $(n=9)$ of the mycorrhizal colonization percentages of the avocado plants at harvest. Different capital letters indicate significant differences $(P<0.05)$ between the inoculation treatments.

\section{Discussion}

We found statistically significant differences and complex factor interactions for most variables measured, but the differences were so small that they may have little significance for rootstock producers. The very low responses of avocado rootstocks to the mycorrhizal inoculants potentially occurred due to two reasons. First, the nurseries use soil instead of potting media. The soils used for rootstock production in Michoacán are mainly high quality andosols that are rarely nutrient deficient. Andosols in the avocado region have high fertility with medium to high levels of available soil phosphorus (Vega-Fraga, 2011; Cortés-González et al., 2012). We found medium soil phosphorus levels although it has been suggested that these types of soils that originate from volcanic ashes and likely contain P-fixing minerals, such as allophane, may have low available P (Montoya and Osorio, 2009; Borie et al. 2010). In contrast to our study, these authors observed a positive response to mycorrhizal colonization in avocado plants under low and medium phosphorus availability and a negative response under high fertilization when using P-deficient soils as a potting medium.

In addition, the large "criollo" avocado seeds, which usually weigh between 10 and $25 \mathrm{~g}$ (dry weight), contain large amounts of nutrient reserves. For example, nitrogen and phosphorus represent an average of $1-2 \%$ and $0.03-0.3 \%$ of the fruit dry mass (Bárcenas et al., 2003), respectively, and $\mathrm{N}$ accounts for approximately $1 \%$ of the dry mass of the seed (Weatherby and Sorber, 1931). Such a large amount of nutrients allows plants that receive only light and water to grow as well as fertilized plants between three and five months, depending on the seed weight (Gavito et al., unpublished data).

Among the variables shown, stem diameter is considered the best indicator of plant vigor among producers because periodical trimming results in 
variable height and foliage. Other avocado cultivars have shown positive responses to inoculation (cv. Topa Topa: Menge et al., 1980; cvs. Santana, Lorena and Común: Montañez-Orozco, 2009) and a moderate dependency on mycorrhizae (cv. Villagorgona, Montoya and Osorio, 2009). Several studies have reported the beneficial effects of mycorrhizal inoculation in avocado rootstocks and young plants (Menge et al., 1978, 1980; Vidal et al., 1992; Silva and Siqueira, 1991; Da Silveira et al., 2002; Montañez-Orozco, 2009; Carreón-Abud et al. 2014). Most of these studies involved inoculation on seeds at sowing or on recently germinated seedlings and the inoculated plants became well-colonized and showed clear growth promotions. However, other studies have observed minor or no responses of rootstocks to inoculation with mycorrhizal fungi (Reyes-Alemán et al., 2001; Bañuelos et al., 2013).

We did not include nonmycorrhizal controls in this study because Mexican nurseries (in contrast with nurseries in the USA (Menge et al., 1980) and Spain (Vidal et al., 1992)) do not use commercial substrates without mycorrhizal propagules. In addition, mycorrhizal inoculants should be able to establish in roots and show their effects when interacting with the native mycorrhizal propagules to justify additional inoculation. In other studies, low amounts of mycorrhizal propagules (or their absence) or low substrate fertility justified the need for inoculation. In the work reported by Bañuelos et al. (2013), we tested several inoculants in one-month old seedlings and found, six months after the inoculation, no differences between the control and the inoculated plants using both sterile and non-sterile soil. However, in another study we performed inoculating two-month old plants through the removal of the soil upper layer and the addition of an inoculum:soil suspension to the roots, only one of the twelve inoculants tested did not increase plant biomass after seven months (Carreón-Abud et al., 2014). That study was also carried out in plants grown in non-sterile soil, indicating that inoculation at the right time can be successful even when performed in plants that have been growing in fresh soil with native propagules. It seems that waiting until the seed reserves have been exhausted is important and plants become more responsive to inoculation as they grow older. The use of seeds obtained from natural pollination to make avocado rootstocks in Mexican nurseries is a healthy practice that ought to be maintained to ensure genetic variability and resistance in avocado plantations. The use of cuttings would be easier to handle in many ways, including the mycorrhizal inoculation procedure, but would not have those long-term advantages.

In our study, only two of the inoculation treatments, Cetraspora pellucida and the avocado orchard native AMF community, showed a slight growth promotion over the control treatment that contained the soil's own AMF community. This finding suggests that the soil already contained efficient AMF and that none of the inoculated alternatives substantially improved this growth stage. The use of forest soil in the nursery, without exposure to fertilization, may explain the efficiency of the soil native AMF community. Both AMF communities are diverse, at least in terms of spore morphotypes, and are dominated by species belonging to the Diversisporales. However, the introduced community was the only one that had been exposed to fertilization and heavy fertilization, as the one applied to avocado orchards, may favor parasitic AMF species (Johnson, 2010).

Most AMF commercial inoculants contain species of the Glomeraceae, a family that is dominant in temperate regions (Öpik et al. 2010), is easy to propagate and is successful for improving the growth and nutrition of a large number of cultivated plants. However, avocado trees require mild environmental conditions (Gutiérrez-Contreras et al., 2010) and 
only develop in tropical and subtropical regions where AMF communities are highly diverse and have a more balanced composition including species from most families (Varela and Trejo, 2001; Stürmer and Siqueira 2011; Cortés-González et al. 2012). Consequently, a variety of isolates have been tested on avocado. Positive effects of Glomus (Montoya and Osorio, 2009; Montañez-Orozco, 2009; RiveraEspinosa et al., 2011), Acaulospora (MontañezOrozco, 2009) and Dentiscutata species (Da Silveira et al., 2002) and negative effects of Gigaspora species (Da Silveira et al., 2002) have been reported. Da Silveira et al. (2002) tested a variety of AMF species in disinfected soil and found that Dentiscutata heterogama, was the best growth promoter and that Glomus and Acaulospora species were also good growth promoters. The increase in biomass, despite being significant, was low $(<20 \%)$ in relation to the control. The effects of inoculating an entire AMF community are more difficult to interpret since AMF species may interact positively, negatively or neutrally as a result of all possible competitive and synergistic combinations. Therefore, a positive effect of the native AMF community is understood as an overall beneficial community as a result of mainly synergistic interactions between the AMF and the host plant although there may be competition between some specific species.

Despite the low response of avocado plants to mycorrhizal inoculations in the nursery stage described above, the first months of the nursery stage remain ideal for inoculating avocado plants. Efficient inoculation is nearly impossible to achieve once plants have reached a height of $1 \mathrm{~m}$ or have been transplanted in the field (Reyes-Alemán et al., 1997). The multiple benefits of mycorrhizal symbiosis to avocado orchards are still unexplored because previous studies have been limited to growth and nutrition surveys. Only one study, for example, investigated the resistance to transplant injury (Menge et al., 1978) and found that mycorrhizae increased it.

The mycorrhizal dependency of our "criollo" variety is unknown. However, we know that its response to mycorrhizal inoculation with many different isolates is low during the first six months from this study and Bañuelos et al. (2103) and Carreón et al. (2014). We believe that mycorrhizal inoculation with either efficient native propagules or with mycorrhizal inoculants (when native communities are absent, or clearly inefficient) should be encouraged in nurseries to ensure that symbiosis is established from the beginning, despite that fact that no clear growth enhancements were observed at this stage. If mycorrhizae with "efficient" symbionts are not established from the beginning, plants may become colonized by inefficient symbionts due to the heavy fertilization regimes that are used in the late nursery stage and when plants are transplanted to orchards. For example, the plants could be colonized by nearly parasitic AMF that proliferate in high fertility environments (Johnson, 2010).

In most of the inoculation treatments, the proportion of leaves that were attacked by herbivores was generally low and showed that more herbivory occurred under the low and medium fertilization treatments. However, the proportion of leaves that were attacked by pathogens increased with the fertilization rate. Fertilization with chicken manure, which is becoming increasingly popular due to its competitive price and reliability relative to compost-based organic fertilizers, was demonstrated to be a good organic fertilizer option when not applied in large amounts. Other studies testing high fertilizer doses have already reported growth depressions (Tanwar et al., 2013) and other problems associated with excessive use of organic fertilizers associated to the release of salts (Reyes-Alemán et al., 2001; Mattar et al., 2003). 
This result provides a strong argument for promoting lower early fertilizer applications in nurseries because high doses are expensive, unnecessary and result in reduced plant growth and increased pathogen damage on avocado leaves.

Several factors may influence the result of mycorrhizal inoculations, and some of these results may depend on the local management context. Thus, the native mycorrhizal propagules, substrate quality and fertility, and the type of fertilizer and seed reserve play important roles in the selection of the right procedures and timing for the efficient inoculation of avocado plants in nurseries. From a practical standpoint, it is easier to inoculate plants as early as possible. However, it should be considered that 1) excessive fertilization (actually unnecessary during the first two months) could inhibit the establishment of mycorrhizal colonies in roots and that 2) inoculation should not be performed too early to ensure that the mycorrhizal propagules do not senesce before the plants can allow the mycorrhizal fungi to initiate colonization, a process that can take several months in avocado plants (Garciarreal-Sánchez, 2012; Gavito et al., unpublished data).

\section{Conclusions}

Minor responses of "criollo" avocado plants to the inoculation and fertilization treatments were observed during the first months in the nursery. Only two of the inoculation treatments, Cetraspora pellucida and the native avocado orchard AMF community, showed slight, though not significant, growth promotion over the control treatment that contained the native soil AMF community. This finding suggests that the "criollo" avocado is not responsive to mycorrhizal inoculation or that the soil already contained efficient
AMF. The second option would explain why none of the alternatives substantially improved this growth stage. Chicken manure may remain a good option as an organic fertilizer if it is not applied in large amounts. High doses in direct application, as it is the common practice, reduced the plant growth and increased the susceptibility of the avocado leaves to plant pathogens.

We suggest that mycorrhizal inoculation with efficient local symbionts (those promoting growth or at least not causing growth depression) should be encouraged in nurseries, despite the lack of clear growth promotion. Inoculation should be performed to ensure that the roots are colonized with compatible, efficient AMF when they are transplanted to in the field and that the multiple benefits of mycorrhizal symbiosis are expressed during the many years of tree growth in the avocado orchards.

\section{Acknowledgements}

We thank the PROMEP-SEP Red de Inoculantes micorrízicos and CONACYT-FOMIX-Michoacán 2009-115994 projects for financially supporting this research.

\section{References}

Anguiano, C. J., Alcántar, J. J. R., Toledo, R. B., Tapia, M. V. L., Ruiz, A. C. J., Rodríguez, C. Y. 2006. Caracterización edafo-climática del área productora de aguacate de Michoacán. Libro Técnico N0. 4. INIFAP-CIRPAC. Prometeo Editores, Guadalajara, México, 188p.

Bañuelos, J., Trejo, D., Lara, L., Gavito, M., Carreón, Y. 2013. Effects of seven different mycorrhizal inoculum in Persea americana in sterile and non-sterile soil. Tropical and Subtropical Agroecosystems. 16, 423-429. 
Bárcenas, O.A.E., Molina, E.J., Huanosto, M.F., Aguirre, P.S. 2003. Contenido de macro y microelementos en hojas, flor y fruto de aguacate "Hass" en la región de Uruapan, Michoacán. In: Proceedings V World Avocado Congress. Granada-Málaga, Spain, pp: 365-371.

Borie, F., Rubio, R., Morales, A., Curaqueo, G., Cornejo, P. 2010. Arbuscular mycorrhizae in agricultural and forest ecosystems in Chile. J. Soil Sci. Plant Nutr. 10, 185-206.

Bravo-Espinosa, M., Mendoza, M.E., CarlónAllende, T., Medina, L., Sánchez-Reyes, J.T., Páez, R. 2014. Effects of converting forest to avocado orchards on top-soil properties in the trans-Mexican volcanic system, Mexico. Land Degradation and Development. 25, 452-467.

Carreón-Abud, Y., Aguirre-Paleo, S., Gavito, M., Mendoza-Solís, D. J., Juárez-Chávez R., Martínez-Trujillo, M., Trejo-Aguilar, D. 2014. Arbuscular mycorrhizal inoculation in avocado rootstocks cv 'Hass' in nurseries of Michoacan, Mexico. Revista Mexicana de Ciencias Agrícolas. 5, 847-857.

Cortés-González, J.C., Vega-Fraga, M., VarelaFregoso, L., Martínez-Trujillo, M., CarreónAbud, Y., Gavito, M.E. 2012. Arbuscular mycorrhizal fungi (AMF) communities and land use change: the conversion of temperate forests to avocado plantations and maize fields in central Mexico. Fungal Ecol. 5, 16-23.

Da Silveira, S.V., de Souza, P.V.D., Koller, O.C. 2002. Influência de fungos micorrízicos arbusculares sobre o desenvolvimento vegetativo de portaenxertos de abacateiro. Pesquisa Agropecuaria Brasileira. 37, 303-309.
Garciarreal-Sánchez, A. 2012. Evaluación de inoculantes micorrízicos y tratamientos de suelo para la producción orgánica de planta de aguacate (Persea americana) en vivero. B. Sc Thesis in Environmental Sciences, Universidad Nacional Autónoma de México. 110 pp.

Gerdeman, J.W., Nicolson, T.H. 1963. Spores of Mycorhizal Endogone species extracted from soil by wet sieving and decanting. Trans. Br. Mycol. Soc. 46, 235-244.

Gianninazzi, S., Gollote, A., Binet, M.N., Van Tuinen, D., Redecker, D., Wipf, D. 2010. Agroecology: the key role of arbuscular mycorhizas in ecosystem services. Mycorrhiza. 20, 519-530.

Gutiérrez-Contreras, M., Lara-Chávez, M.B.N., Guillén-Andrade, H., Chávez-Bárcenas, A.T. 2010. Agroecología de la franja aguacatera en Michoacán, México. Interciencia. 35, 647-653.

Johnson, N. C. 2010. Resource stoichiometry elucidates the structure and funtion of arbuscular mycorrhizas across scales. New Phytol. 185, 631-647.

Mattar, M., Hernández, C., Castro, M. 2003. Effect of mycorrhiza inoculation (Glomus intraradices Schenck \& Smith) on avocado plantlets in the nursery. V World Avocado Congress Abstracts A-173, 397p.

McGonigle, T. P., Miller, M. H., Evans, D. G., Fairchild, G. L., Swan, J. A. 1990. A new method which gives an objective measure of colonization of roots by vesicular-arbuscular mycorrhizal fungi. New Phytol. 15, 495-501.

Menge, J.A., Davis, R.M., Johnson, E.L.V., Zentmyer, G. A. 1978. Mycorrhizal fungi increase growth and reduce transplant injury in avocado. Calif. Agricul. 32, 6-7. 
Menge, J.A., La Rue, J., Labanauskas, C.K., Johnson, E.L.V. 1980. The effect of two mycorrhizal fungi upon growth and nutrition of avocado seedlings grown with six fertilizer treatments. J. Am. Soc. Hort. Sc. 105, 400-404.

Montañez-Orozco, B.I. 2009. Efecto de la micorrización en plantas de aguacate (Persea americana) durante la fase de vivero en suelos provenientes de los Llanos Orientales. M. Sc. Thesis, Universidad Nacional de Colombia, 125 p.

Montoya, B., Osorio, W. 2009. Mycorrhizal dependency of avocado at different levels of soil solution phosphorus. In: III Congreso latinoamericano del aguacate Proceedings. Medellín, Colombia, pp: 19-31.

Öpik, M., Vanatoa, A., Vanatoa, E., Moora, M., Davison, J., Kalwij, J.M., Reier, Ü., Zobel, M. 2010. The online database MaarjAM reveals global and ecosystemic distribution patterns in arbuscular mycorrhizal fungi (Glomeromycota). New Phytol. 188, 233-241.

Phillips, J. M., Hayman, D.S. 1970. Improved procedure for clearing roots and staining parasitic and vesicular-arbuscular mycorrhizal fungi for rapid assessment of infection. Trans. Br. Mycol. Soc. 55, 158-161.

Reyes-Alemán, J.C., Alarcón, A., Ferrera-Cerrato R. 1997. Aspectos relacionados sobre el uso de la endomicorriza arbuscular en aguacate (Persea americana Mill). Memoria, Fundación Salvador Sánchez Colín CICTAMEX. Coatepec Harinas México, pp: 83-94.

Reyes-Alemán, J. C., Ferrera-Cerrato, R., Alarcón A. 2001. Aplicación de vermicomposta y hongos micorrízicos en la producción de planta de aguacate en vivero. CICTAMEX 1998-2001, pp: 80-87.
Rivera-Espinosa, R.A., Martin-Cárdenas, J.V., Calderón-Puig, A., Torrez-Hernández, A. 2011. Utilización de cepas eficientes de hongos micorrízicos arbusculares en el desarrollo de portainjertos de aguacate en un sustrato suelocachaza. Cultivos Tropicales. 32, 172-183.

SIAP-SAGARPA. 2010. Servicio de Información Agroalimentaria y Pesquera de la Secretaría de Agricultura, Ganadería, Desarrollo Rural, Pesca y Alimentación. URL was not included as specified in instructions to authors. Consulted on may 2012.

Silva, L.C., Siqueira, J.O. 1991. Growth and nutrient contents of avocado, mango and papaya seedlings under the influence of different vesiculararbuscular mycorrhiza fungal species. Revista Brasileira de Ciencia do solo. 15, 283-288.

Stürmer, S.L., Siqueira, J.O. 2011. Species richness and spore abundance of arbuscular mycorrhizal fungi across distinct land uses in western Brazilian Amazon. Mycorrhiza. 21, 255-267.

Tanwar, A., Aggarwal, A., Kadian, N., Gupta, A. 2013. Arbuscular mycorrhizal inoculation and superphosphate application influence plant growth and yield of Capsicum annum. J. Soil Sci. Plant Nutr. 13, 55-66.

Treseder, K. K. 2004. A meta-analysis of mycorrhizal responses to nitrogen, phosphorus and atmospheric $\mathrm{CO}_{2}$ in field studies. New Phytol. 164, 347-356.

Varela, L., Trejo, D. 2001. Los hongos micorrizógenos arbusculares como componentes de la biodiversidad del suelo en México. Acta Zoológica Mexicana. Número Especial. 1, 39-51.

Vega-Fraga, M. 2011. Diversidad de hongos micorrizógenos arbusculares y potencial micorrízico de dos agroecosistemas y una zona natural del estado de Michoacán. M. Sc. Thesis, Universidad Michoacana de San Nicolás de Hidalgo, 117p. 
Verbruggen, E., van der Heijden, M.G.A., Rillig, M.C., Kiers, E.T. 2013. Mycorrhizal fungal establishment in agricultural soils: factors determining inoculation success. New Phytol. 197, 1104-1109.
Vidal, M.T., Azcón-Aguilar, C., Barea, J.M. 1992. Mycorrhizal inoculation enhances growth and development of micropropagated plants of avocado. Hortscience. 27, $785-787$.

Weatherby, L.B., Sorber, D.G. 1931. Chemical composition of avocado seeds. Ind. Eng. Chem. $23,1421-1423$. 